Supporting Information

\title{
Effect of cell culture media on photopolymerizations
}

Marzieh Monfared, ${ }^{a}$ Mitchell D. Nothling, ${ }^{a}$ Damia Mawad, ${ }^{b}$ Martina H. Stenzel, ${ }^{a *}$

a School of Chemistry, UNSW Sydney, NSW, 2052, Australia, M.Stenzel@unsw.edu.au

${ }^{\mathrm{b}}$ School of Materials Science and Engineering, UNSW Sydney, NSW, 2052 Australia

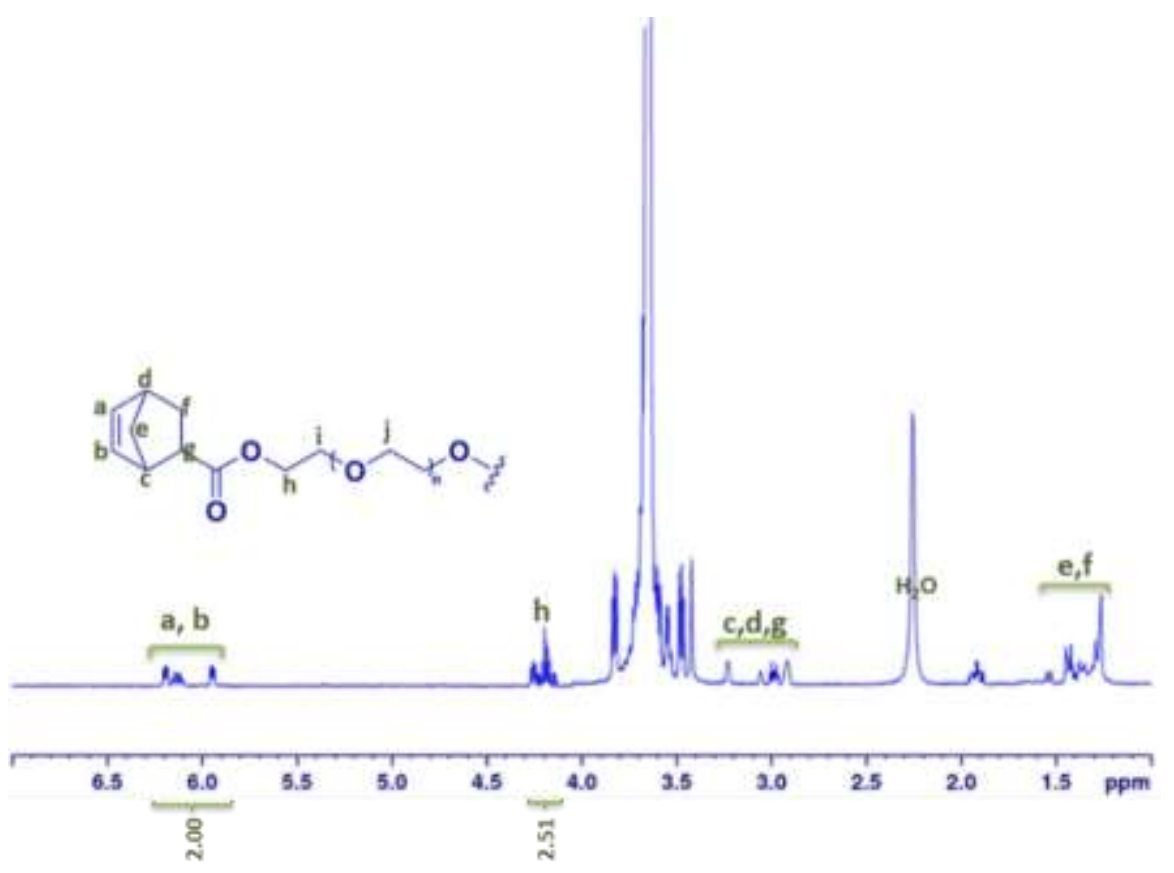

Figure S1. ${ }^{1} \mathrm{H}-\mathrm{NMR}$ spectra of 4PEG-NB 
Table S1. Components of commercial Sigma cell culture media

\begin{tabular}{|c|c|c|}
\hline Sigma media number & DMEM (D0422) & DMEM (D1145) \\
\hline Components & $\mathrm{g} / \mathrm{L}$ & $\mathrm{g} / \mathrm{L}$ \\
\hline $\mathrm{CaCl} 2$ & 0.265 & 0.265 \\
\hline $\mathrm{Fe}(\mathrm{NO} 3) 3.9 \mathrm{H} 2 \mathrm{O}$ & 0.0001 & 0.0001 \\
\hline MgSO4 & 0.09767 & 0.09767 \\
\hline $\mathrm{KCl}$ & 0.4 & 0.4 \\
\hline $\mathrm{NaHCO} 3$ & 3.7 & 3.7 \\
\hline $\mathrm{NaCl}$ & 6.4 & 6.4 \\
\hline $\mathrm{NaH} 2 \mathrm{PO} 4$ & 0.109 & 0.109 \\
\hline L-Arginine $\bullet \mathrm{HCl}$ & 0.084 & 0.084 \\
\hline L-Cystine $\bullet 2 \mathrm{HCl}$ & - & 0.0626 \\
\hline Glycine & 0.03 & 0.03 \\
\hline L-Histidine $\bullet \mathrm{HCl} \bullet \mathrm{H} 2 \mathrm{O}$ & 0.042 & 0.042 \\
\hline L-Isoleucine & 0.105 & 0.105 \\
\hline L-Leucine & 0.105 & 0.105 \\
\hline L-Lysine $\bullet \mathrm{HCl}$ & 0.146 & 0.146 \\
\hline L-Methionine & - & 0.03 \\
\hline L-Phenylalanine & 0.066 & 0.066 \\
\hline L-Serine & 0.042 & 0.042 \\
\hline L-Threonine & 0.095 & 0.095 \\
\hline L-Tryptophan & 0.016 & 0.016 \\
\hline L-Tyrosine $\bullet 2 \mathrm{Na} \bullet 2 \mathrm{H} 2 \mathrm{O}$ & 0.12037 & 0.12037 \\
\hline L-Valine & 0.094 & 0.094 \\
\hline Choline Chloride & 0.004 & 0.004 \\
\hline Folic Acid & 0.004 & 0.004 \\
\hline Myo-Inositol & 0.0072 & 0.0072 \\
\hline Niacinamide & 0.004 & 0.004 \\
\hline D-Pantothenic Acid • $1 / 2 \mathrm{Ca}$ & 0.004 & 0.004 \\
\hline Pyridoxine $\bullet \mathrm{HCl}$ & 0.00404 & 0.00404 \\
\hline
\end{tabular}




\begin{tabular}{lcc}
\hline Riboflavin & 0.0004 & 0.0004 \\
\hline Thiamin $\bullet \mathrm{HCl}$ & 0.004 & 0.004 \\
\hline D-Glucose & 4.5 & 4.5 \\
\hline Phenol Red $\bullet \mathrm{Na}$ & 0.0159 & - \\
\hline Pyruvic Acid $\bullet \mathrm{Na}$ & 0.11 & - \\
\hline L-Glutamine & 0.584 & 0.584
\end{tabular}

Table S2. The concentration range of different media for different photoreactions under UV and blue light irradiation

\begin{tabular}{|c|c|c|c|c|c|c|c|c|c|c|}
\hline Photoreaction & & & & Media & once & ratio & $\mathrm{v} / \mathrm{v}^{0}$ & & & \\
\hline DMA polymerization under UV light & 10 & 20 & 30 & 40 & 50 & 60 & 70 & 80 & 90 & 100 \\
\hline DMA polymerization under blue light & 10 & - & - & - & 50 & - & - & - & - & 100 \\
\hline PEGDA free radical photohydrogelation & - & 20 & - & 40 & - & 60 & - & - & - & - \\
\hline $\begin{array}{l}\text { PEG-NB thiol-ene photohydrogelation } \\
\mathrm{pH}=7.2\end{array}$ & - & - & 30 & - & - & - & 70 & - & - & 100 \\
\hline $\begin{array}{l}\text { PEG-NB thiol-ene photohydrogelation } \\
\mathrm{pH}>8\end{array}$ & 10 & 20 & 30 & - & - & - & - & - & - & - \\
\hline
\end{tabular}

Table S3. The concentration range of different chain transfer agents and their calculated chain transfer constants for DMA linear photopolymerization

$$
\text { Chain transfer agents Concentrations range }(\mathrm{mM}) \quad \text { Chain Transfer Constant }\left(\mathrm{C}_{\mathrm{tr}}\right)
$$

$\begin{array}{lll}\text { L-cysteine } & 0.2-9 & 0.001074\end{array}$


L-tryptophan

thiamine

pyridoxine

folic Acid

riboflavin

L-tyrosine

L-histidine

BSA
$0.0078-0.78$

$0.012-1.2$

$0.02-1$

0.0009-0.009

0.001-0.1

0.05-5

$0.2-20$

0.01-0.06
0.0001812

0.0000189

0.003088

0.01418

0.005985

0

0

0.001422 


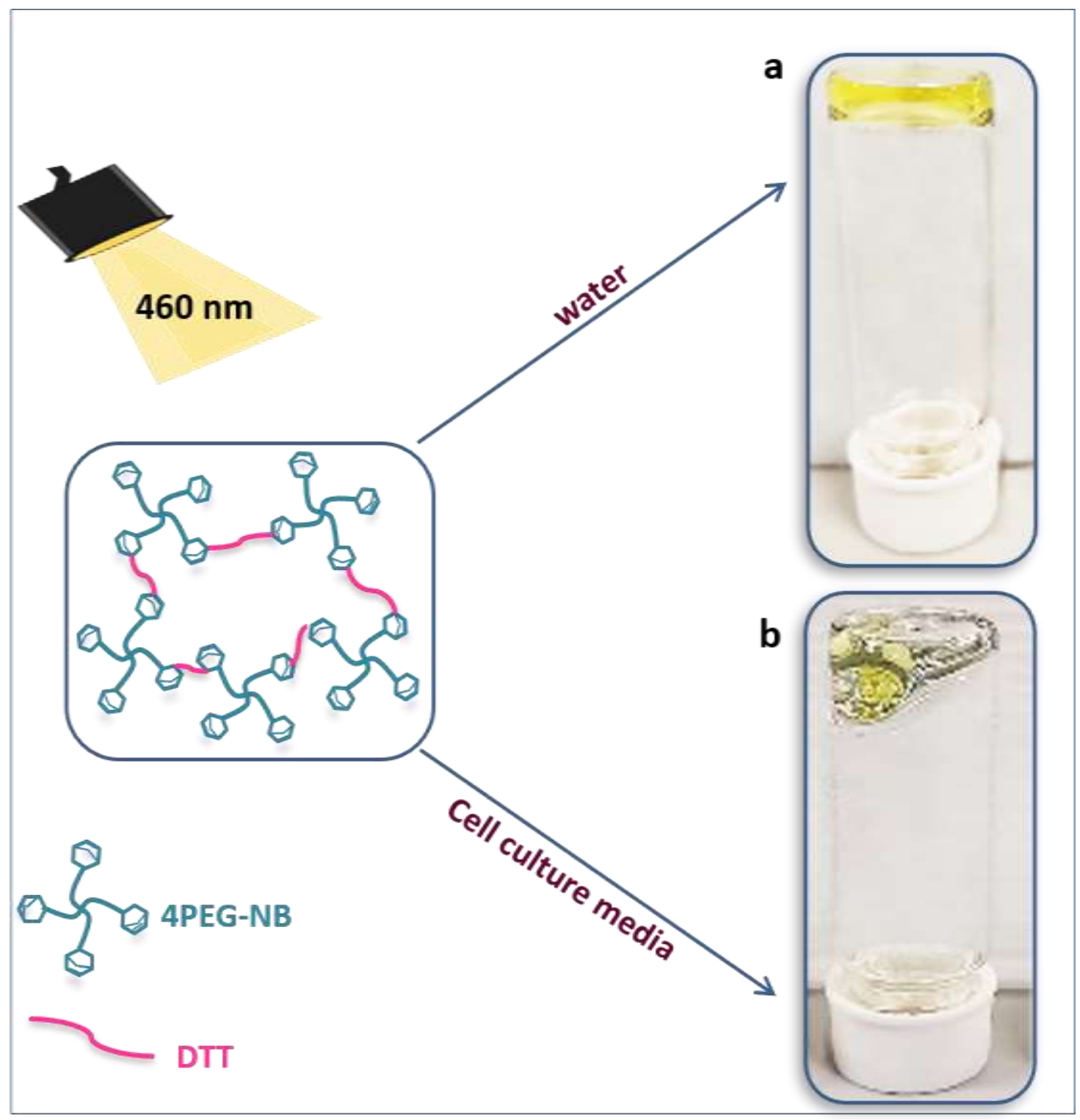

Figure S2. Radical thiol-ene photogelation of 4PEG-NB in (a) Milli-Q water, and (b) cell culture media. The hydrogel stiffness is severely affected by culture media. 


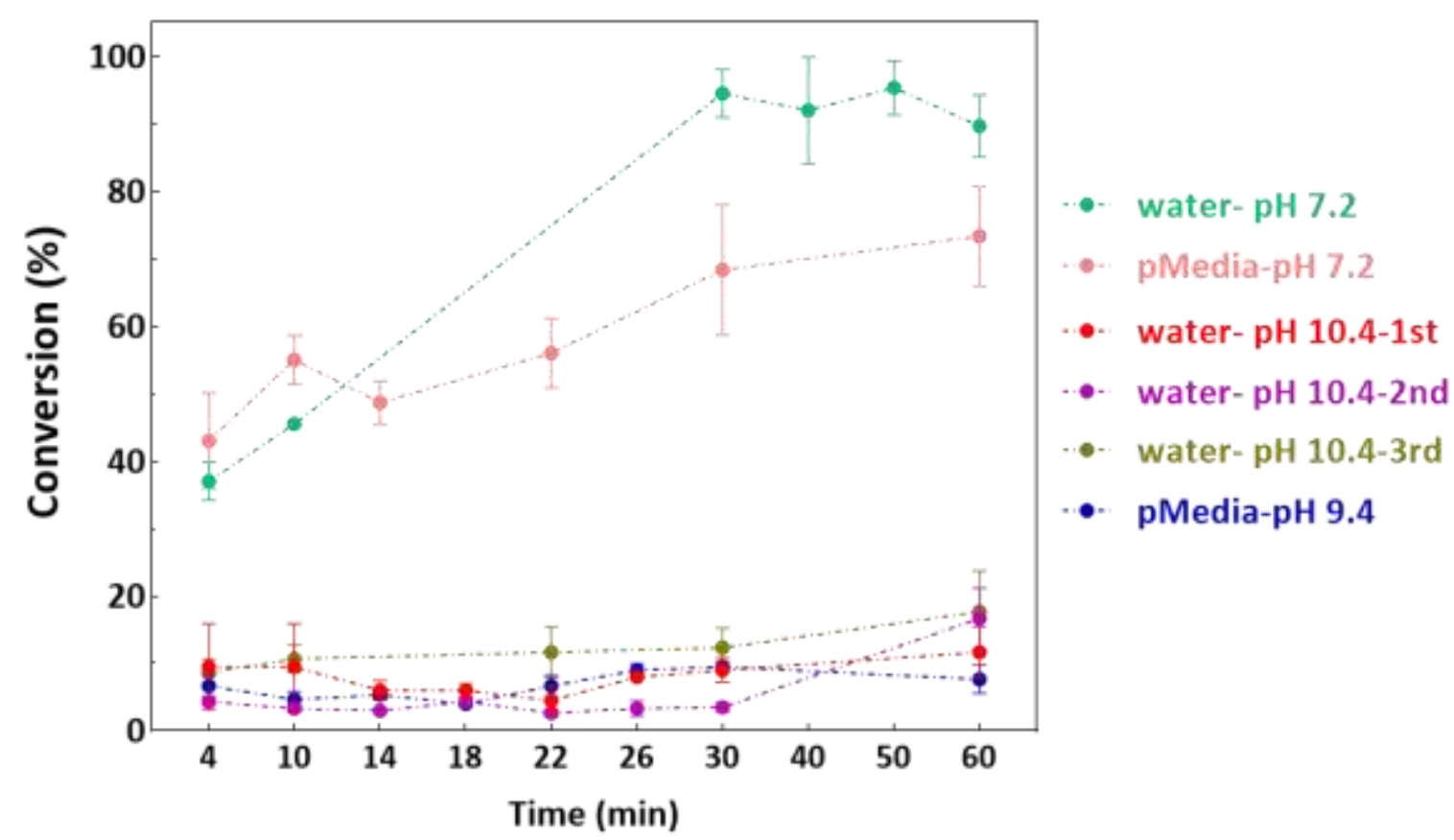

Figure S3. Effect of $\mathrm{pH}$ environment on the conversion of PDMA at a different time of photopolymerization.

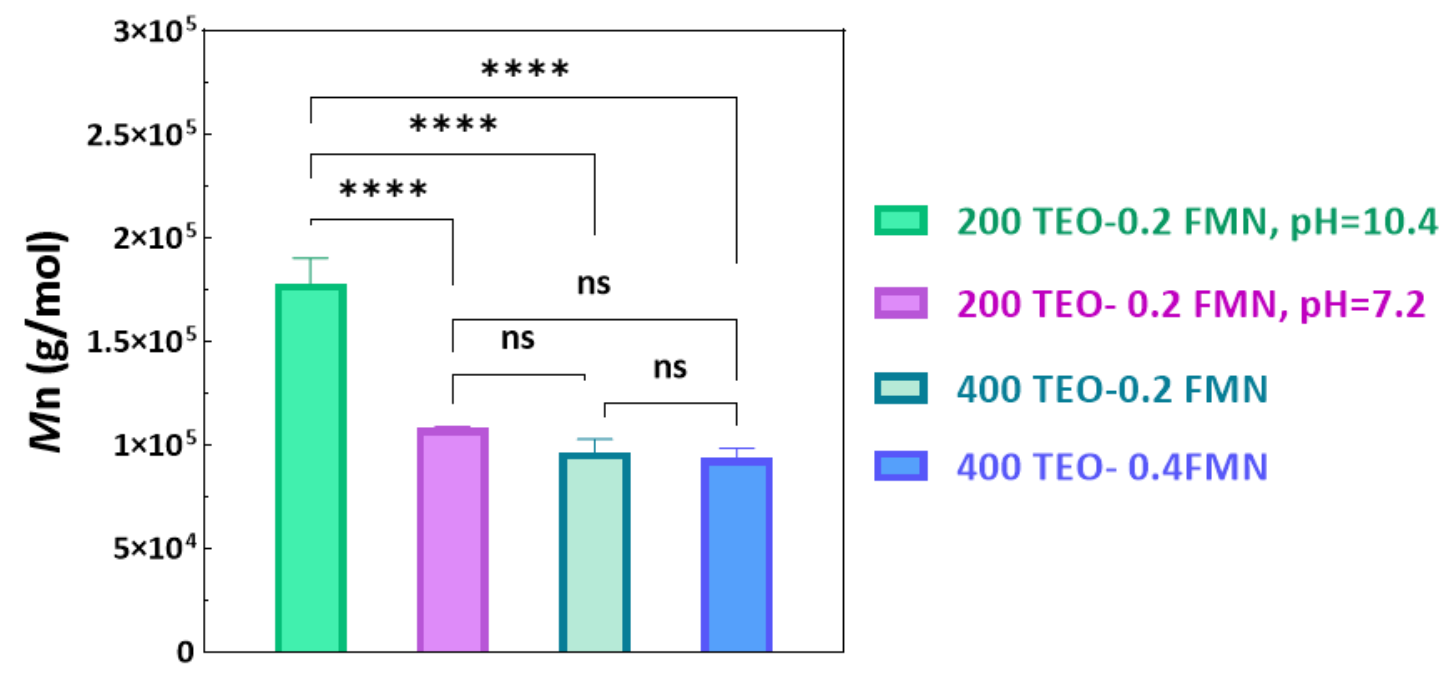

Figure S4. Effect of concentration of the TEO/FMN, and $\mathrm{pH}$ on the molecular weight of PDMA contains $100 \%$ pMedia. The numbers near TEO and FMN show the concentration in $\mathrm{mM}$. 

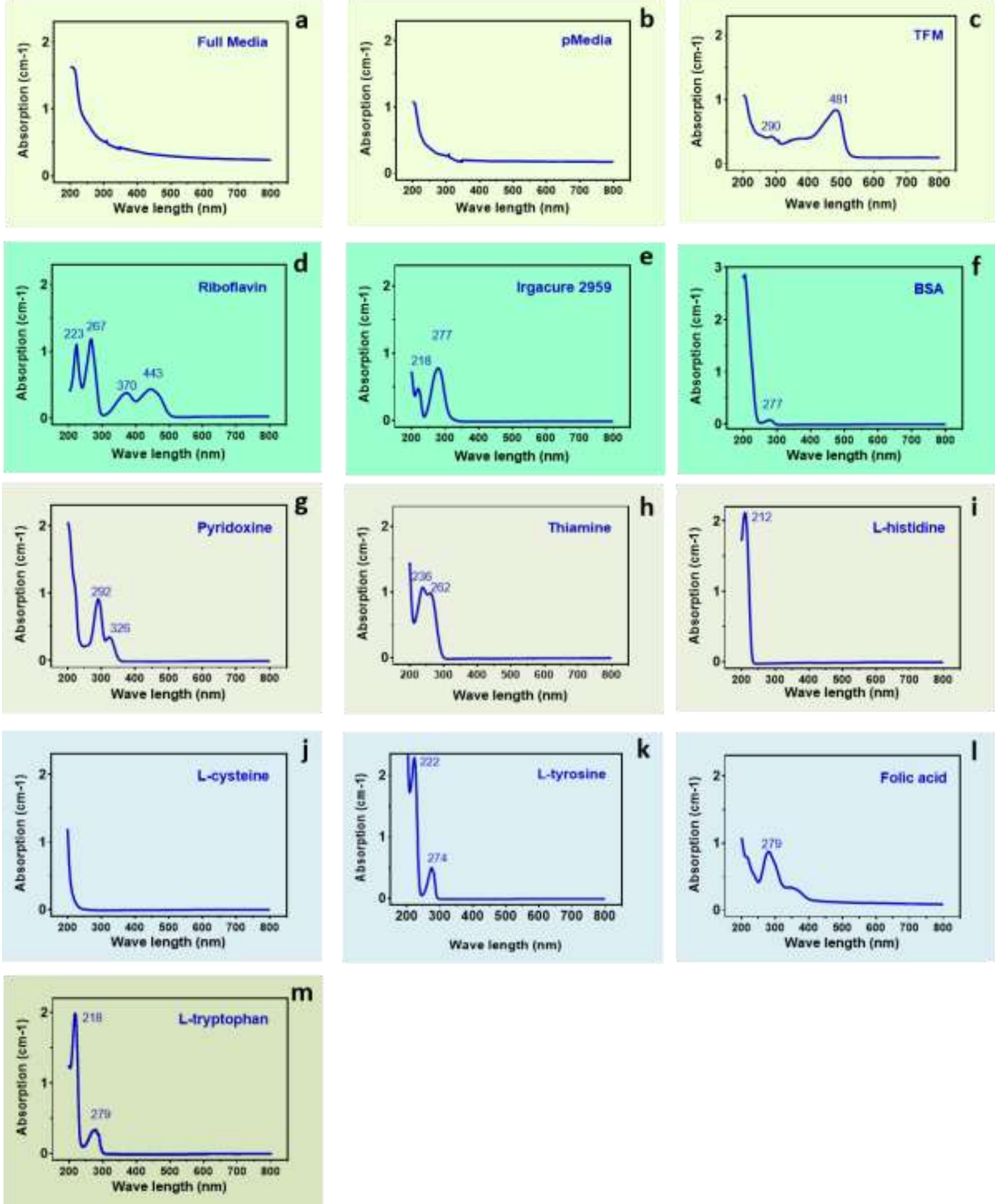

Figure S5. UV/Vis absorption spectra of Irgacure $(0.1 \mathrm{mM})$, cell culture media components, and different types of media 


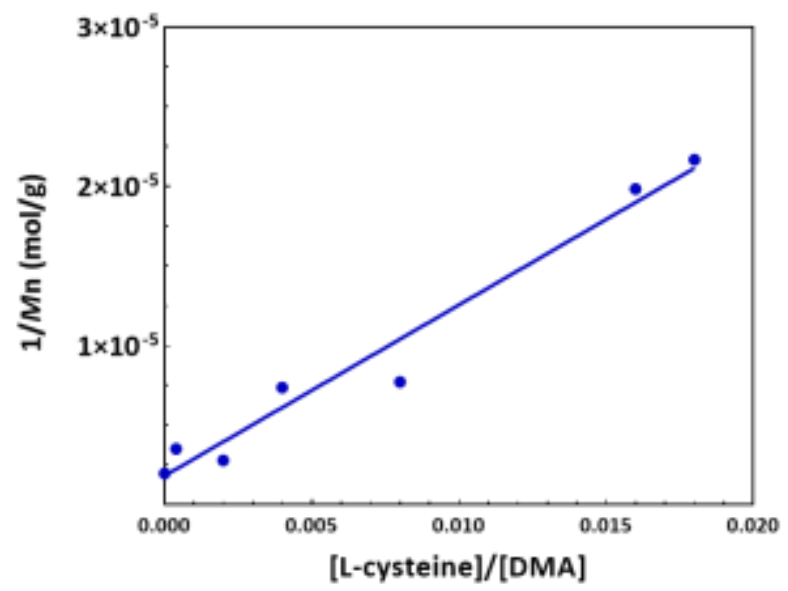

Figure S6. The Mayo plot shows the change of molecular weight of PDMA over L-cysteine concentration. The slope of the Mayo plot indicates the chain transfer constant $\left(\mathrm{C}_{\mathrm{tr}}\right)$ of Lcysteine. 

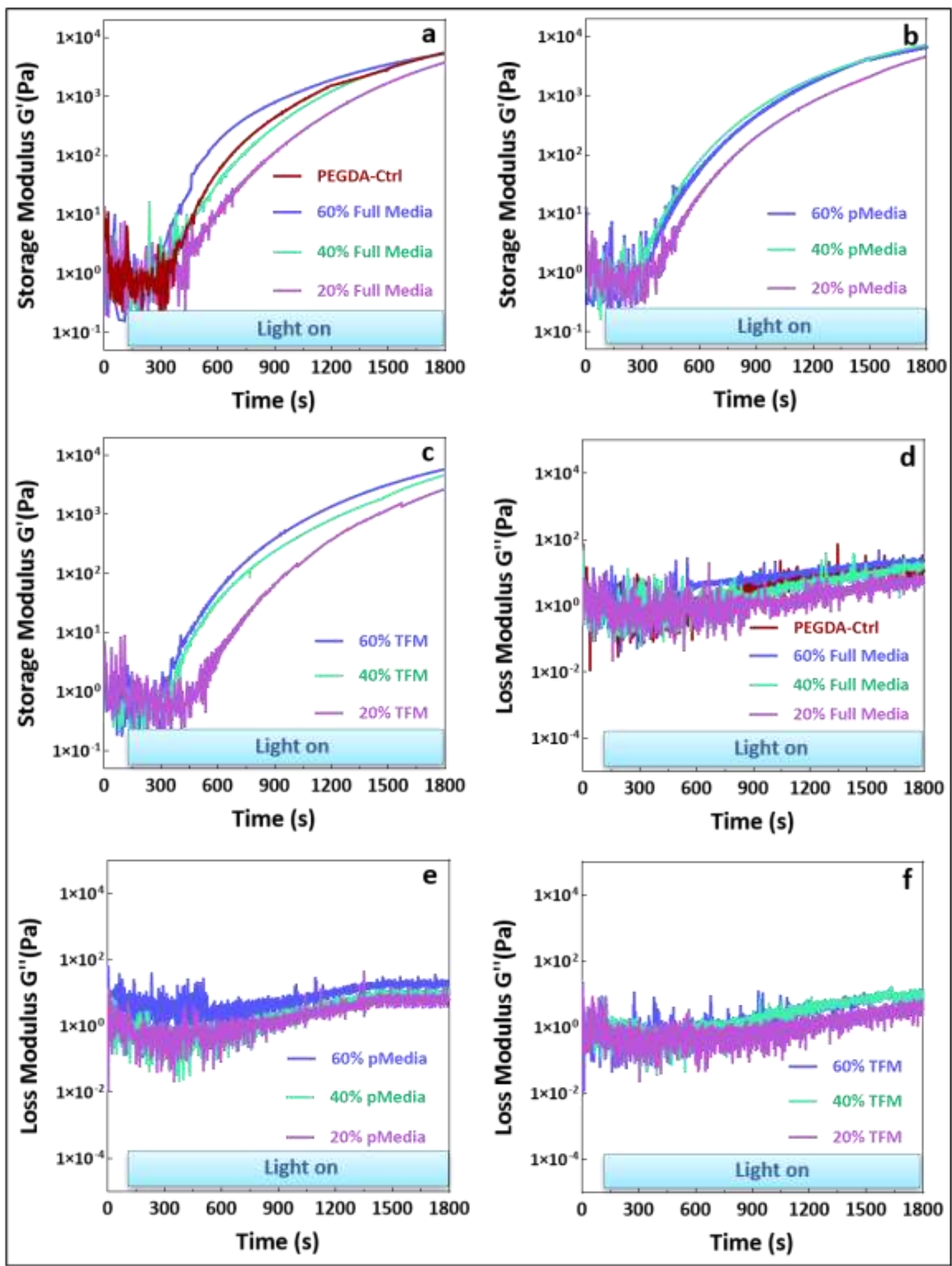

Figure S7. Rheological properties of free radical photohydrogelation of PEGDA. Change of storage and loss moduli of the PEGDA hydrogel after blue light irradiation under oscillatory analysis. The light was switched on at 120th s and continued until $1800 \mathrm{~s}$. The storage modulus 
of (a) control group and Full Media (b) pMedia, (c) TFM. Loss Modulus of (d) control group and Full Media (e) pMedia and (f) TFM.

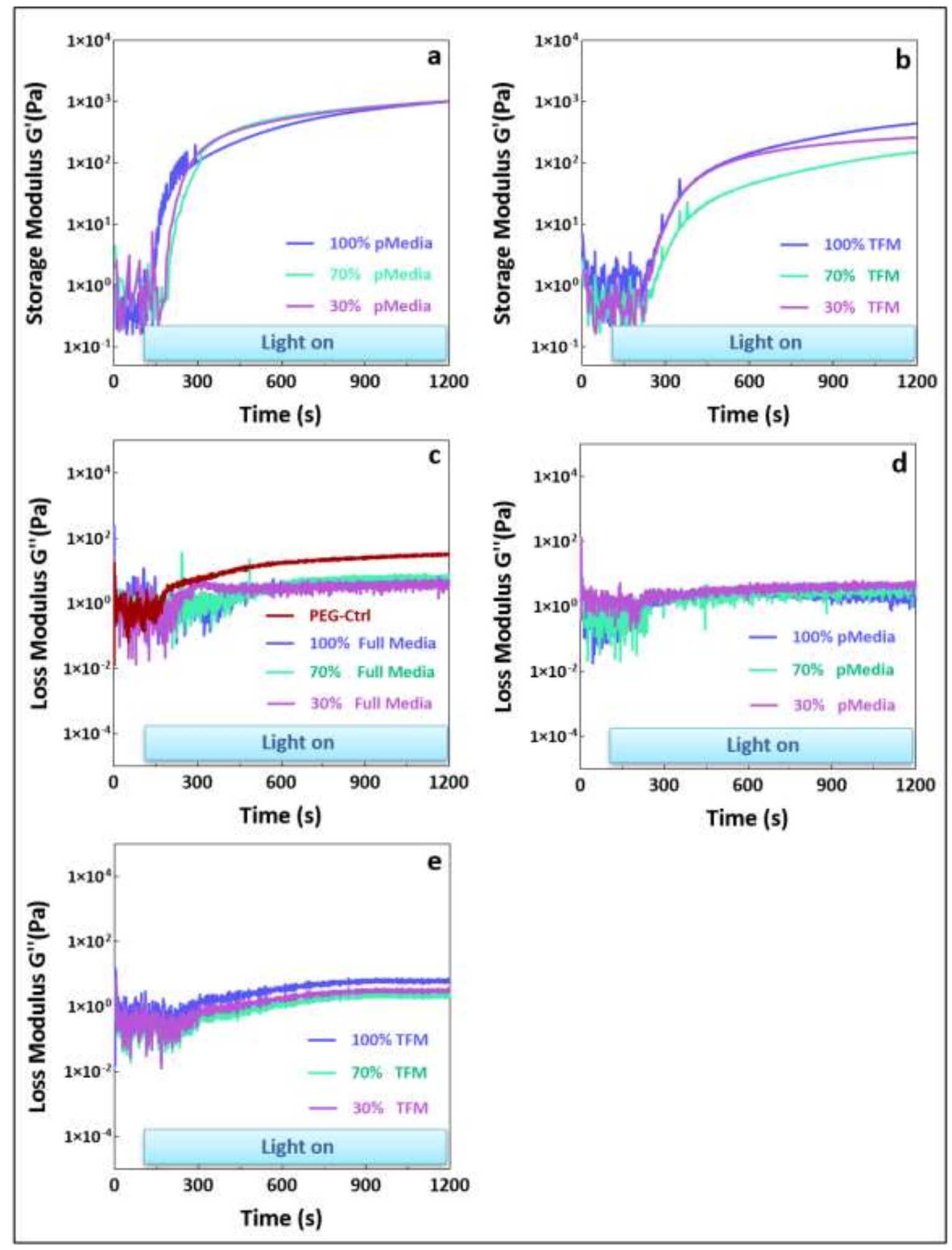


Figure S8. Rheological properties of thiol-ene photohydrogelation of PEG-NB hydrogel at $\mathrm{pH}=7.2$. Change of storage and loss moduli of the PEG-NB hydrogel after blue light irradiation under oscillatory analysis. The light was switched on at 120th s and continued until $1200 \mathrm{~s}$. Storage modulus of (a) pMedia, (b) TFM. Loss Modulus of (c) PEG- Ctrl and Full Media, (d) pMedia, (e) TFM.

Table S4. $\mathrm{pH}$ of different commercial Sigma cell culture media 


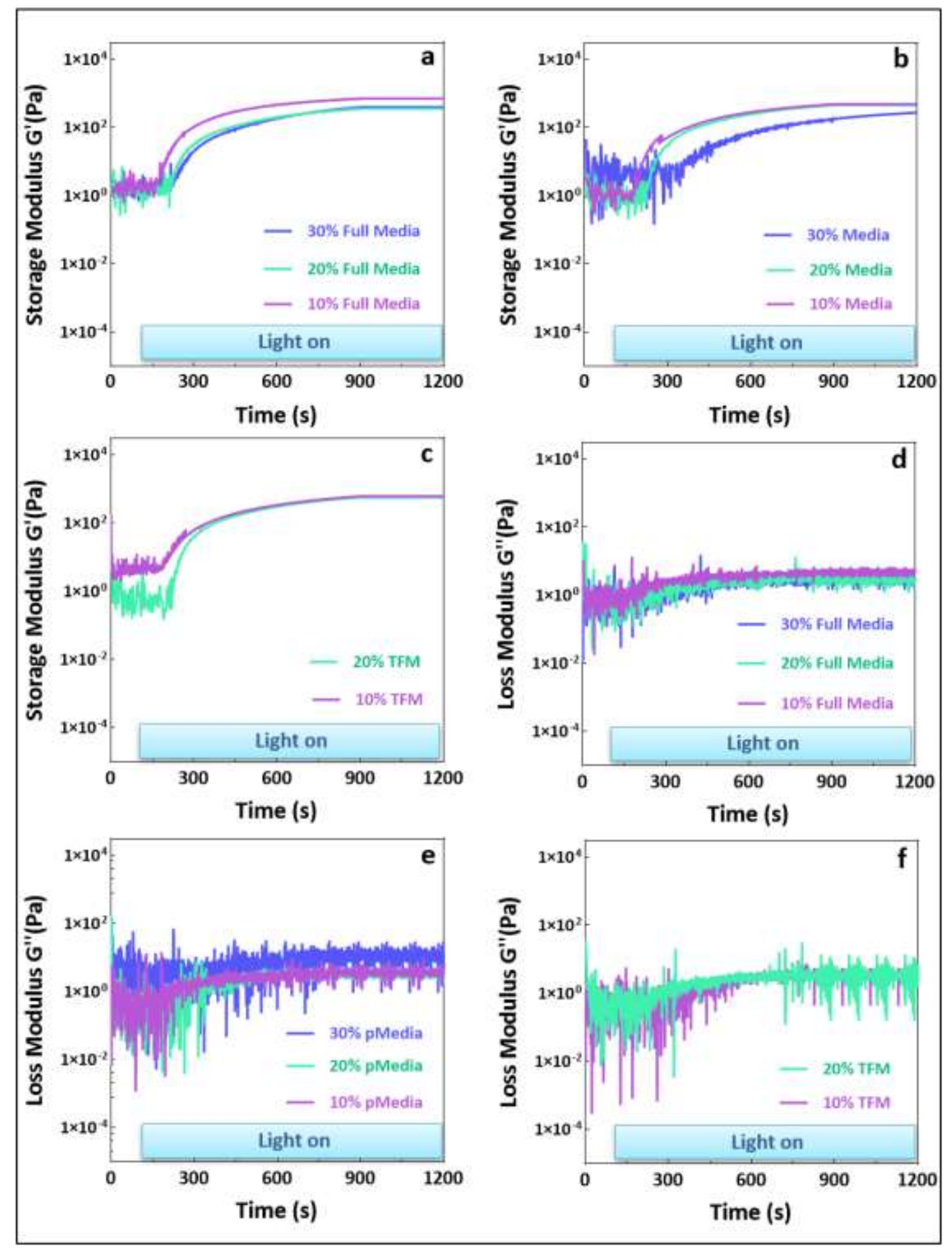

Figure S9. Rheological properties of thiol-ene photohydrogelation of PEG-NB hydrogel at $\mathrm{pH}>8$. Change of storage and loss moduli of the PEG-NB hydrogel after blue light irradiation under oscillatory analysis. The light was switched on at 120th s and continued until $1200 \mathrm{~s}$. 
Storage Modulus of (a) Full Media, (b) pMedia (c) TFM. Loss Modulus of (d) Full Media, (e) pMedia, and (f) TFM. 